\title{
Knockdown of Trio by CRISPR/Cas9 suppresses migration and invasion of cervical cancer cells
}

\author{
CONGZHE HOU ${ }^{1 *}$, ZIRONG ZHUANG $^{2 *}$, XINCHAO DENG ${ }^{1}$, YUEQIN XU $^{3}$, \\ PING ZHANG ${ }^{1 * *}$ and $\mathrm{LIN} \mathrm{ZHU}^{1 * *}$ \\ ${ }^{1}$ Department of Gynecology, The Second Hospital of Shandong University, Jinan, Shandong 250033; \\ ${ }^{2}$ The Third Department, Jinan Infectious Disease Hospital, Jinan, Shandong 250021; \\ ${ }^{3}$ Department of Child Healthcare, Shandong Qianfoshan Hospital, Jinan, Shandong 250014, P.R. China
}

Received July 27, 2017; Accepted November 24, 2017

DOI: $10.3892 /$ or.2017.6117

\begin{abstract}
Triple functional domain protein (Trio) is an evolutionarily conserved protein with guanine nucleotide exchange factors that regulate different physiological processes in some types of cancer. However, the expression and function of Trio in cervical cancer are still unknown. The purpose of this study was to detect the expression of Trio in cervical cancer tissues and to evaluate its clinical value. Furthermore, the effects of the Trio on the migration and invasion of cervical cancer cells and its mechanism were investigated in vitro. The results of the present study revealed that Trio expression levels were significantly higher in most of the clinical cervical cancer samples than in adjacent tissues. The clinicopathological significance of Trio expression was also analyzed, and the results revealed that high expression levels in cervical cancer were correlated with lymph node metastasis $(\mathrm{P}=0.005)$. The CRISPR/Cas9 system was used to knockdown the endogenous Trio. The inhibition of Trio significantly decreased the migration and invasion abilities of cervical cancer cells. Meanwhile, levels of RhoA/ROCK signaling factors (RhoA, Rock, and p-LIMK), which contributed to cell migration and invasion, were decreased along with the inhibition of Trio. Therefore, Trio may regulate the migration and invasion of cervical cancer through the RhoA/ROCK signaling pathway.
\end{abstract}

\section{Introduction}

Triple functional domain protein (Trio) is a large evolutionarily conserved protein that harbors a serine/threonine kinase domain and two guanine nucleotide exchange factor

Correspondence to: Dr Lin Zhu, Department of Gynecology, The Second Hospital of Shandong University, Jinan, Shandong 250033, P.R. China

E-mail: sdey_zhulin2015@163.com

${ }^{*, * *}$ Contributed equally

Key words: Trio, cervical cancer, migration, invasion
(GEF) domains (1). The two GEF domains activate the GTPases Rac1/RhoG and RhoA, potentially linking several Rho-GTPase signaling pathways (2). Trio participates in the regulation of different physiological processes, most notably in neuronal physiology (3-7). In addition to its main effects on neuronal development, Trio plays important roles in other aspects of myogenesis and phagocytosis (8-10). Since Trio controls a wide range of cellular processes, dysregulation of its activity is related to the emergence of diseases. Trio was demonstrated to be highly upregulated in urinary bladder tumors (11), soft tissue sarcomas (12), breast cancer (13), and various other types of cancer (11-19). Higher Trio levels were closely related to invasive tumor phenotype, high tumor grade, and rapid tumor cell proliferation in breast tumors (13). A high expression level of Trio was also associated with clinicopathological parameters and poor prognosis of hepatocellular carcinoma patients. Trio was also expressed at higher levels in glioblastoma compared with low-grade glioma and was related to poor patient survival (17). Concomitantly, Trio was capable of serving as a prognostic marker, which helped in determining the therapeutic modality of colorectal cancer patients (19).

Cervical carcinoma is the second most common cause of cancer mortality in females and seriously affects the health of women worldwide (20). Tumor metastasis results in $~ 90 \%$ of cancer-related deaths $(21,22)$. For cervical cancer, invasion and migration are important processes in the progression of cancer metastasis (23). Therefore, studies on molecular mechanisms underlying tumor invasion and metastasis are very relevant for understanding tumor occurrence and development. Despite the major advances in therapeutic approaches, most patients still succumb to cancer progression (24-27). Lymph node metastasis acts as an important unfavorable prognostic factor and a primary cause of cancer-related deaths (28). Previous studies have reported that Trio was involved in some types of cancer development (11-19). High expression of Trio was associated with rapid tumor cell proliferation and invasive tumor growth (18). However, studies on the role of Trio and its clinical significance in cervical cancer remain non-existent. In the present study, we identified Trio expression in cervical cancer and its effects on cell invasion and migration. Furthermore, we investigated the mechanism of Trio in cervical cancer migration and invasion. 
Table I. The sequences and location of gRNAs targeting Trio.

Name

Genomic target

Target location

$\begin{array}{ll}\text { g-RNA1 } & \text { TCCGCCGCTGCTGCCGCTCATGG } \\ \text { g-RNA2 } & \text { GCCGCGCTGGCCGCCGCGGCGGG } \\ \text { g-RNA3 } & \text { CACCTCTGAGCCAGGGATACTGG }\end{array}$

Exon 1

Exon 1

g-RNA3

CACCTCTGAGCCAGGGATACTGG

Exon 24

\section{Materials and methods}

Tissue specimens and cell lines. All procedures adhered to the approved medical ethics practices and the Human Ethics Review Board of the Second Hospital of Shandong University, China [Approval no.: KYLL-2014 (LW) P-001]. Clinical specimens were collected from patients at the Second Hospital of Shandong University from October 2014 to December 2016. Histological classifications and clinical staging were based on the classification system by the International Federation of Gynecology and Obstetrics (International Federation of Gynecology and Obstetrics Cancer Committee; FIGO, 2009) (29). A tumor size of $4 \mathrm{~cm}$ was chosen as a 'watershed' value according to previous studies (30-32). The human cervical cancer cell lines, Caski and HeLa, and normal cervical cell, CRL-2614, were purchased from the Cell Bank of the Chinese Academy of Sciences (Shanghai, China). The cells were grown in RPMI-1640 medium supplemented with $10 \%$ fetal bovine serum (FBS) at $37^{\circ} \mathrm{C}$ and $5 \% \mathrm{CO}_{2}$. Transfection was performed with Lipofectamine 2000 reagent (Invitrogen; Thermo Fisher Scientific, Waltham, MA, USA) following the manufacturer's protocols.

Reverse transcription-quantitative polymerase chain reaction analysis. Total RNA was isolated from tissue and cells using TRIzol reagent (Invitrogen), according to manufacturer's protocols. Total RNA (1 $\mu \mathrm{g})$ was reverse-transcribed into cDNA using PrimeScript RT reagent kit (Takara Biotechnology Co., Ltd., Dalian, China), and qPCR was conducted using SYBR-Green dye mix (Invitrogen). Thermocycling conditions for RT-qPCR were as follows: $95^{\circ} \mathrm{C}$ for $10 \mathrm{~min}, 40$ cycles of $95^{\circ} \mathrm{C}$ for $20 \mathrm{sec}, 55^{\circ} \mathrm{C}$ for $30 \mathrm{sec}$, and $72^{\circ} \mathrm{C}$ for $20 \mathrm{sec}$. The relative expression level of Trio was calculated using $2^{-\Delta \Delta \mathrm{Cq}}$, and the expression level of Trio mRNA was normalized to that of GAPDH. The Trio sense and antisense primers were designed as follows: 5'-AGATTCTCTGTCGTTAAG-3', and 5'-TTCTA AGACCAGGATGTA-3', respectively. The GAPDH sense and antisense primers were: 5'-CTCAAGATCATCAGCAAT-3' and 5'-CGATACCAAAGTTGTCAT-3', respectively.

CRISPR/Cas9 system targeting human Trio. The guide RNA sequences targeting the human Trio gene were designed using an online sgRNA design tool at https://crispr.mit.edu/. Guide sequences with high scores for on-target activity and minimal predicted off-target activity were selected. Table I displays the three sets of oligonucleotides. Primer oligonucleotides were annealed under $88^{\circ} \mathrm{C}$ for $2 \mathrm{~min}, 65^{\circ} \mathrm{C}$ for $10 \mathrm{~min}, 37^{\circ} \mathrm{C}$ for $10 \mathrm{~min}$, and $25^{\circ} \mathrm{C}$ for $5 \mathrm{~min}$. The annealing primer was then purified and cloned into the PX330 vector (Addgene,
Cambridge, MA, USA). The CRISPR/Cas9 backbone and CRISPR/Cas9-gRNA plasmids were separately transfected into cells using a lipidosome.

In vitro invasion assay. For the invasion assay, a Transwell chamber placed into a 24-well plate was coated with $30 \mu \mathrm{l}$ of Matrigel and incubated for $40 \mathrm{~min}$ at $37^{\circ} \mathrm{C}$. In the Transwell assay, the cells were trypsinized and seeded in chambers at a density of $5 \times 10^{5}$ cells/well and were cultured in serum-free medium, while $500 \mu \mathrm{l}$ of $10 \%$ FBS-RPMI-1640 were added to the lower chamber. After $24 \mathrm{~h}$, the cells on the upper surface were removed, and the migrated cells were fixed with $100 \%$ methanol for $30 \mathrm{~min}$. The cells on the bottom surface of the membrane were stained with eosin for $20 \mathrm{~min}$. The cell images were obtained under a phase-contrast microscope.

Wound healing assays. Cells were seeded in 6-well plates. When the cells reached $90-100 \%$ confluence, the cell monolayers were wounded by scraping with a micropipette tip. The spreading of wound closure was observed after $48 \mathrm{~h}$. Images were captured using a phase-contrast microscope (Olympus, Tokyo, Japan) either immediately or $48 \mathrm{~h}$ after wounding. All experiments were repeated thrice.

Western blot analysis. Western blot analysis was performed using anti-Trio (Rabbit, Polyclonal, 1:1,000; Abnova, Taipei, Taiwan), anti-RhoA (Rabbit, monoclonal, 1:1,000, cat. no. 2117; Cell Signaling Technology, Beverly, MA, USA), anti-Rock1 (Mouse, monoclonal, 1:800, cat. no. sc-365628), anti-Rock2 (Mouse, monoclonal, 1:800, cat. no. sc-398519) (both from Santa Cruz Biotechnology, Santa Cruz, CA, USA), and antiLIMK1 (Rabbit, Polyclonal, 1:1,000, cat. no. 3842) antibodies, p-LIMK1 (Thr508) (Rabbit, Polyclonal, 1:1,000, cat. no. 3841) (both from Cell Signaling Technology), with rabbit anti- $\beta$-actin (Mouse, monoclonal, 1:5,000; Bioworld, Nanjing, China) were used as a loading control. Band intensities of the western blotting were analyzed using Image Analysis Software v2.0 (Thermo Fisher Scientific Inc.).

RhoA activation assay. RhoA activity was assessed using a Rho Activation Assay Biochem kit ${ }^{\mathrm{TM}}$ (Cytoskeleton, Inc., Denver, CO, USA) according to the manufacturer's protocol.

Statistical analysis. All values were expressed as the mean \pm SD of three individual experiments. Statistical analyses were performed using Student's t-test. When appropriate, the Mann-Whitney U-test was used to compare the two groups. $\mathrm{P}<0.05$ were considered to indicate a statistically significant result. SPSS software was used for statistical analyses. 


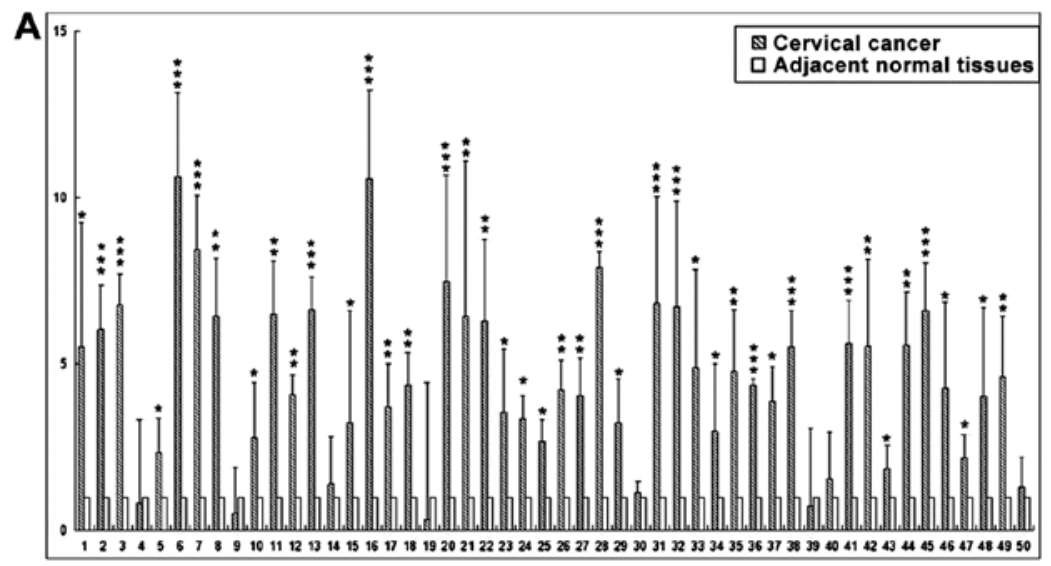

B
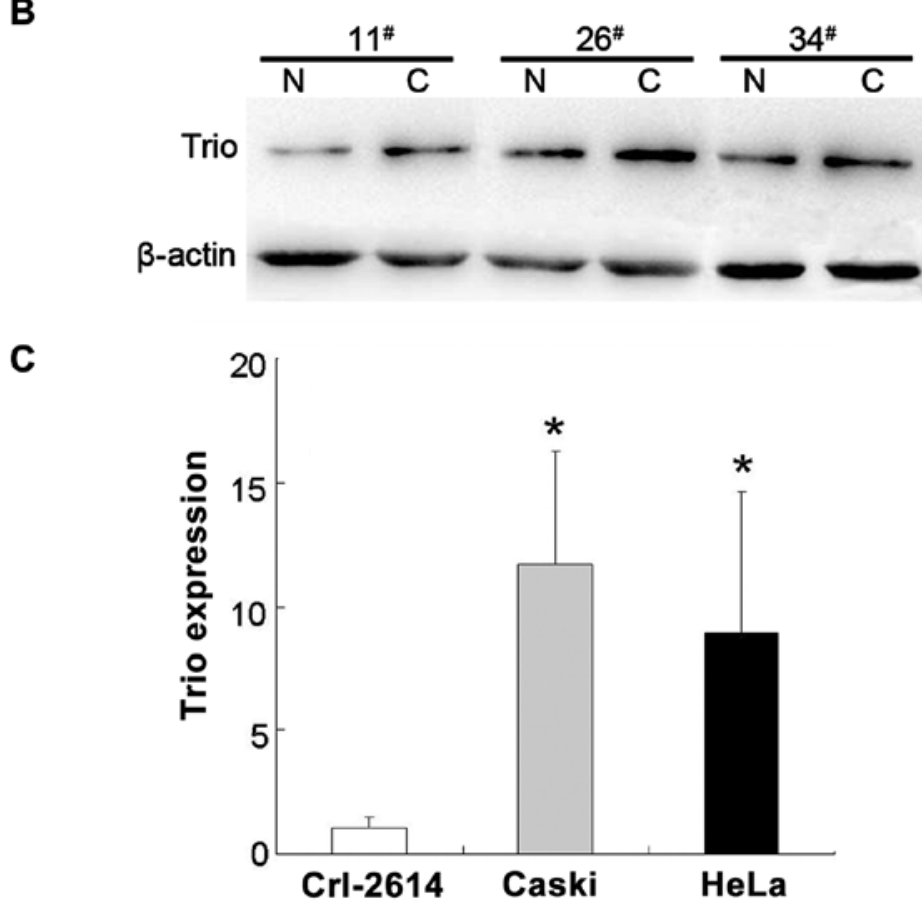

Figure 1. Expression of Trio in cervical cancer tissues and cell lines. (A) Relative mRNA expression of Trio was detected by qRT-PCR in 50 paired human cervical cancer tissues. (B) Trio protein levels in three paired randomly selected cervical cancer tissues and their corresponding adjacent normal tissues were determined using western blot assays. (C) Expression of Trio in normal cervical cell line Crl-2614 and cervical cancer cell lines HeLa and Caski. "P<0.05; ${ }^{* *} \mathrm{P}<0.01 ;{ }^{* * *} \mathrm{P}<0.001$.

\section{Results}

Expression of Trio in cervical cancer biopsies and cell lines. To ascertain Trio expression in cervical cancer, we performed real-time PCR on 50 clinical specimens from cervical cancer patients. The expression levels of Trio in the tumor tissues for all 50 samples were significantly higher than that in the matching adjacent tissue (Fig. 1A). Furthermore, we determined the protein level of Trio in randomly selected cancer and adjacent normal tissues $(n=3)$. The protein level was also increased compared to the normal tissues (Fig. 1B). The expression of Trio was also determined in cervical cancer cell lines (Caski and HeLa) and in a normal cervical cell line (Crl-2614) (Fig. 1C), where the results obtained from the two analyses were in agreement with the data obtained from real-time PCR, indicating the significant increase of Trio levels in cervical cancer tissues and cell lines compared with normal cervical tissue and a cell line.
High expression of Trio in cervical cancer is correlated with tumor metastasis. We analyzed the expression level of Trio to determine its clinicopathological significance. Notably, Trio levels were significantly increased in patients with lymph node involvement $(\mathrm{P}=0.005)$ (Table II). Therefore, Trio expression associates with lymph node metastasis and is a potential diagnostic marker for cervical cancer.

Inhibition of Trio expression by CRISPR/Cas9. We used Caski cells to examine the effects of Trio gene knockdown by CRISPR/Cas9. We transfected Caski cells with the control, CRISPR+Cas9+gRNA empty, CRISPR+Cas9+Trio-1, CRISPR+Cas9+Trio-2, and CRISPR+Cas9+Trio-3 and cultured them for two days. Fig. 2A revealed the transfection results as determined by western blotting, which confirmed the reduced expression of Trio by CRISPR+Cas9-gRNA1 in comparison with the control at $48 \mathrm{~h}$. CRISPR+Cas9+Trio-1 exhibited effective knockdown of Trio gene expression at 
A

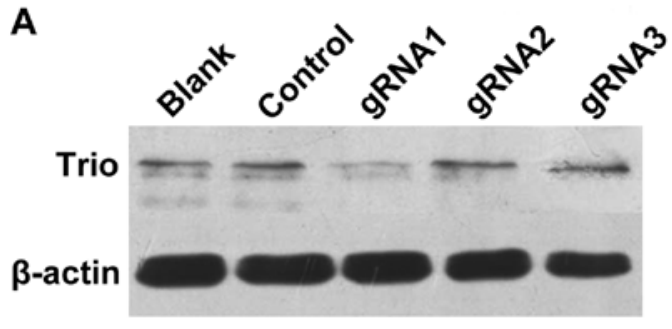

C

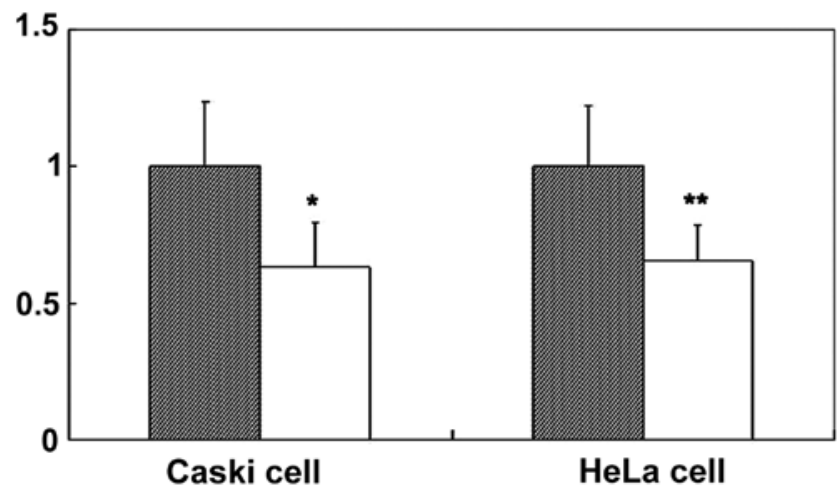

B

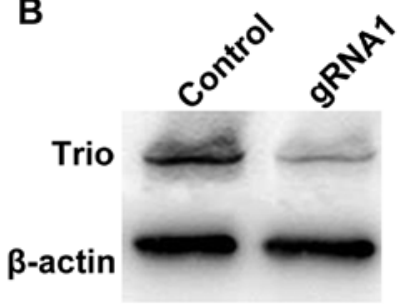

Figure 2. Knockdown of Trio expression by transfection of CRISPR/Cas9. (A) CRISPR+Cas9+Trio-1 exhibited effective knockdown of Trio gene expression in Caski cells. (B) CRISPR+Cas9+Trio-1 exhibited effective knockdown of Trio gene expression in HeLa cells. (C) The data are presented as the mean \pm SD of three independent experiments. Control, gRNA empty vector. ${ }^{*} \mathrm{P}<0.05 ;{ }^{* *} \mathrm{P}<0.01$.

Table II. The association between Trio expression with clinicopathological parameters in 50 cervical cancer patients.

\begin{tabular}{|c|c|c|c|}
\hline Variables & No. & $\begin{array}{c}\text { Trio relative } \\
\text { transcript level } \\
\text { (mean mRNA/GAPDH } \\
\pm \text { standard deviation) }\end{array}$ & $\mathrm{P}$-value \\
\hline Age (years) & & & $0.156^{\mathrm{a}}$ \\
\hline$\leq 50$ & 18 & $0.0336 \pm 0.0309$ & \\
\hline$>50$ & 32 & $0.0360 \pm 0.0239$ & \\
\hline Tumor size $(\mathrm{cm})$ & & & $0.856^{\mathrm{a}}$ \\
\hline$\leq 4$ & 37 & $0.0340 \pm 0.0249$ & \\
\hline$>4$ & 13 & $0.0368 \pm 0.0376$ & \\
\hline FIGO staging & & & $0.983^{b}$ \\
\hline I & 31 & $0.0363 \pm 0.0330$ & \\
\hline II & 10 & $0.0351 \pm 0.0235$ & \\
\hline III-IV & 9 & $0.0361 \pm 0.0257$ & \\
\hline Histological grade & & & $0.996^{\mathrm{b}}$ \\
\hline Well & 13 & $0.0365 \pm 0.0351$ & \\
\hline Moderately & 10 & $0.0365 \pm 0.0321$ & \\
\hline Poorly & 27 & $0.0370 \pm 0.0300$ & \\
\hline $\begin{array}{l}\text { Pelvic lymph node } \\
\text { metastasis }\end{array}$ & & & $0.005^{\mathrm{a}}$ \\
\hline No & 34 & $0.0341 \pm 0.0348$ & \\
\hline Yes & 16 & $0.0423 \pm 0.0299$ & \\
\hline
\end{tabular}

${ }^{\mathrm{a} C}$ Comparisons between groups using the Mann-Whitney test. ${ }^{\mathrm{b}} \mathrm{Com}-$ parisons among three groups performed by one-way analysis of variance (ANOVA). FIGO, International Federation of Gynecology and Obstetrics Cancer Committee.
48 h (Fig. 2A and C). Significantly decreased Trio expression was also demonstrated in the HeLa cell line (Fig. 2B and C) as determined using western blotting. Therefore, we obtained an effective gRNA for Trio.

Knockdown of Trio by CRISPR/Cas9 inhibits cervical cancer cell migration and invasion. Migration assay through wound-healing revealed that the migration ability of Caski and HeLa cells transfected with the control was significantly higher in cervical cancer cells than that of cells transfected with knocked down Trio-1 (Fig. 3).

Invasion assay using the Transwell method revealed that the invasiveness of Caski and HeLa cells transfected with CRISPR+Cas9+Trio-1 was significantly lower than that of cells transfected with the control (Fig. 4). Trio silencing inhibited cervical cancer cell migration and invasion via inactivation of the RhoA/Rock signaling pathway.

Rho-GTPase proteins participate in cell motility and actin cytoskeleton reorganization (18). RhoA is a member of the Rho-GTPase proteins and acts as a switch between the active GTP-bound form and inactive GDP-bound form. The activated RhoA-GTPase is associated with invasive cancers and tumor metastasis $(30,31)$. To determine whether the inactivation of the Rho-GTPase pathway mediated the inhibitory effect of Trio on cervical cancer cell migration and invasion, we examined the expression level of the active RhoA-GTPase under Trio knockdown by western blotting. The active form of GTP-bound RhoA was downregulated after Trio decreased. We assessed the protein levels of ROCK1, ROCK2 and p-LIMK1, a protein directly downstream of ROCK, after transient transfection of CRISPR+Cas9+gRNA empty and CRISPR+Cas9+Trio-1 for $48 \mathrm{~h}$. Knockdown of Trio significantly inhibited the protein expression of activated RhoA, ROCK1, ROCK2 and p-LIMK1 compared with the control (Fig. 5), indicating that Trio may 


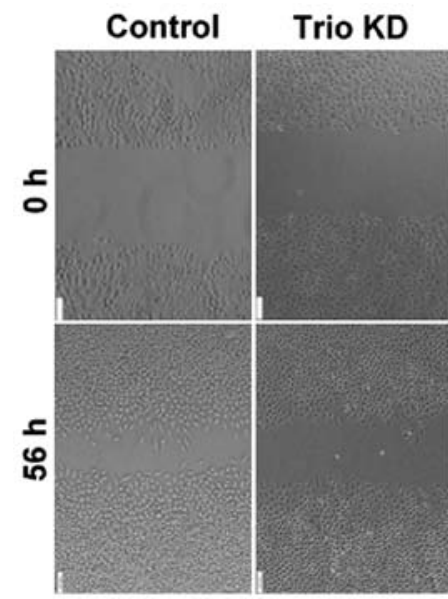

Caski cell

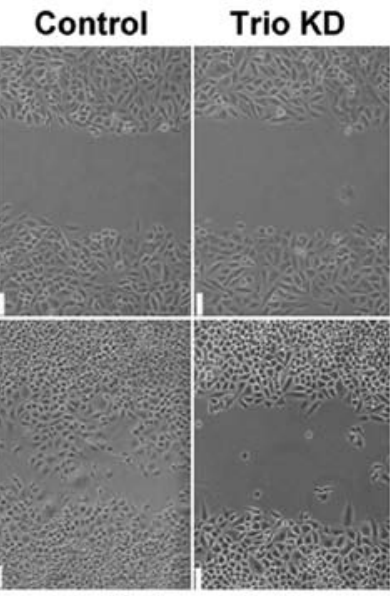

HeLa cell

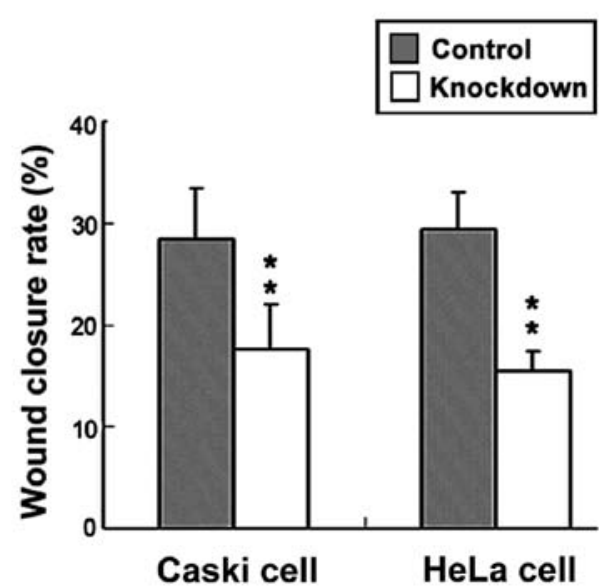

Figure 3. A scratch wound-healing assay was conducted in Caski and HeLa cells transfected with CRISPR+Cas9+Trio-1 (Trio knockdown) or CRISPR+Cas9+gRNA empty (control). The migration distance was assessed at 0 and $56 \mathrm{~h}$ following cell-scratching. Images are viewed under a magnification of $\mathrm{x} 100{ }^{* *} \mathrm{P}<0.05$.
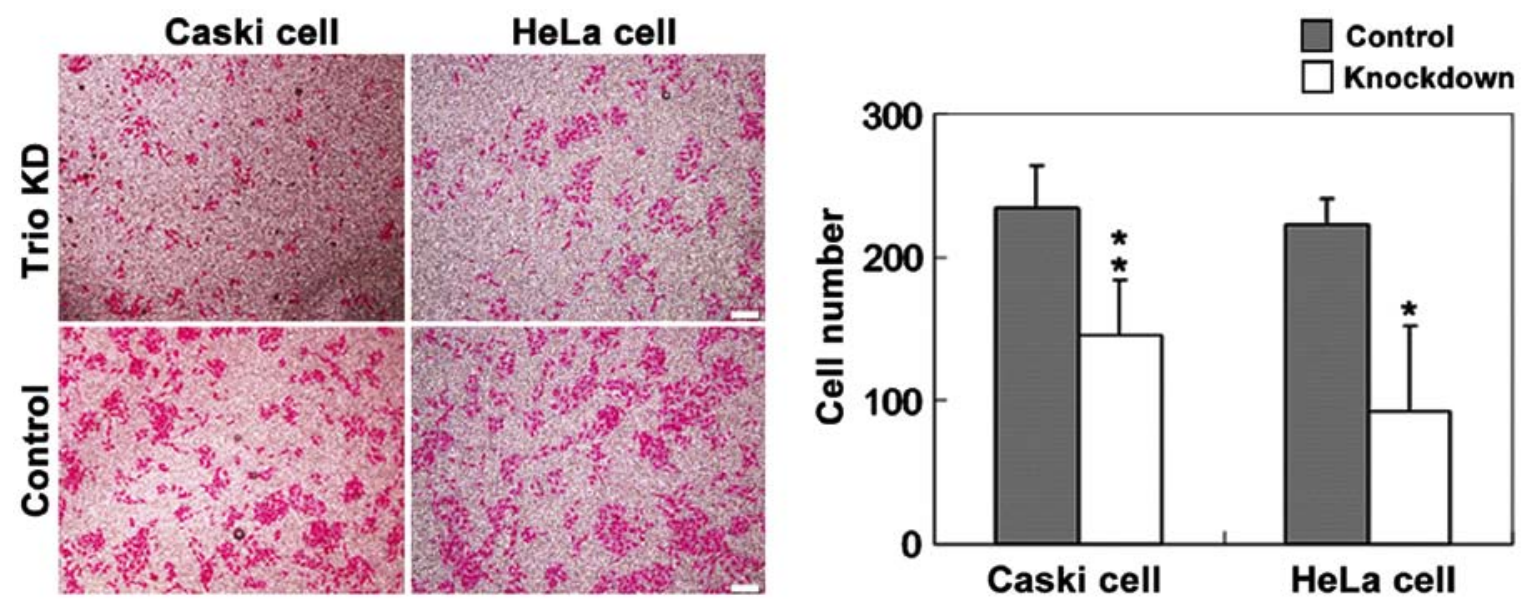

Figure 4. A Transwell assay revealed the invasion capacity of Caski and HeLa cells transfected with CRISPR+Cas9+Trio-1 (Trio knockdown) or CRISPR+Cas9+gRNA empty (control). The cells were stained with $1 \%$ eosin. Images were viewed under a magnification of $x 100$. The average number of invading cells is from three independent experiments. ${ }^{*} \mathrm{P}<0.05 ;{ }^{* *} \mathrm{P}<0.01$.

A

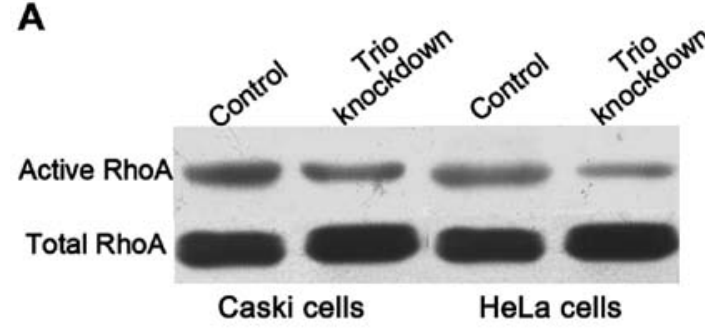

C

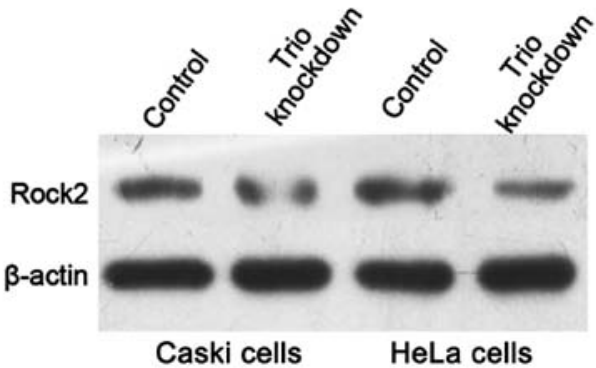

B
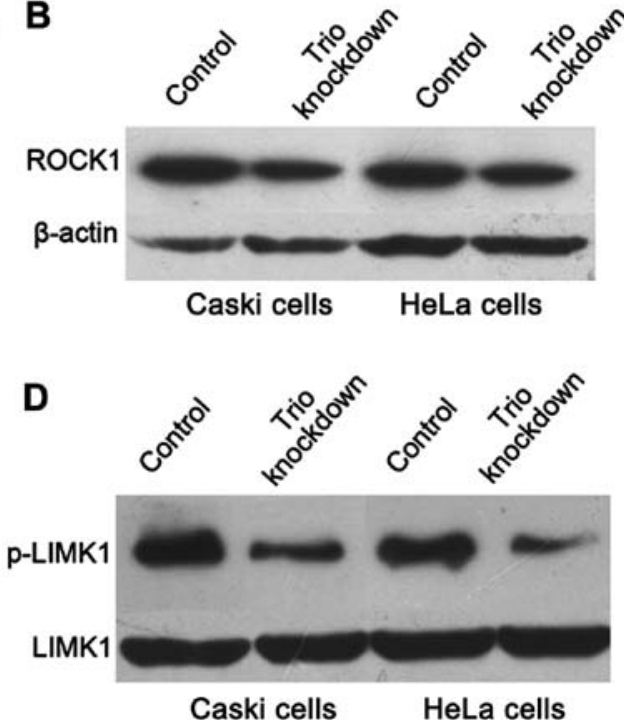

Figure 5. The expression levels of active RhoA, ROCK1, ROCK2, and p-LIMK1 were detected using western blotting in Caski and HeLa cells transfected with CRISPR+Cas9+Trio-1 or the control for $48 \mathrm{~h}$. 
mediate the metastatic ability of cervical cancer cells through inactivation of the RhoA-GTPase pathway.

\section{Discussion}

In the present study, we first determined the mRNA expression levels of Trio in 50 pairs of human cervical cancer tissues and the matching adjacent tissues by qRT-PCR. Our data indicated that Trio expression was higher in cervical cancer tissues than that in adjacent tissues. Consistent with the results of tissue analysis, the expression of Trio at the RNA level was also increased in cervical cancer cell lines compared with the normal cervical cells. Furthermore, the clinicopathological parameters were evaluated to identify the correlation between Trio expression and clinical characteristics. The elevated expression of Trio was significantly associated with lymph node metastasis in cervical cancer patients. Our results revealed that the high expression of Trio was related to lymph node metastasis and serves as a potential diagnostic marker for cervical cancer.

Cell migration and invasion are key features for metastatic dissemination of cancer cells and metastatic formation, which are the leading causes of death in cancer patients (33). In the present study, we performed scratch wound and Transwell invasion assays to examine the effect of Trio expression on cervical carcinoma cell migration and invasion, respectively, and our results revealed that Trio knockdown significantly inhibited cervical cancer cell migration and invasion.

Most cancer cells control their migratory and invasive capabilities by actin cytoskeleton reorganization (34). Rho-family small GTPases, which are activated by guanine nucleotide exchange factors (GEFs), are key regulators of cytoskeleton dynamics $(35,36)$. Trio is a member of the RhoGEFs family, and has two GEF domains, one for RAC (GEF1) and the other (GEF2) for RHO $(1,2)$. The Rho/ROCK signaling pathway participates in tumor growth and metastasis by regulating actin cytoskeleton reorganization $(37,38)$. Western blotting demonstrated that Trio knockdown downregulated the activity of RhoA in Caski and HeLa cells. Previous studies have demonstrated that ROCK kinase, activated by RhoA, is a key regulator of intracellular signaling pathways that contributes to cell migration and invasion. A high expression of ROCK induces migration and invasion in several types of tumor (39-42). In our study, the protein level of ROCK1 and ROCK 2 were also decreased during Trio knockdown. We also examined the phosphorylation of LIM-kinase 1 (LIMK1), which is activated by the small GTPase Rho and its downstream protein kinase ROCK (42) and is important for the regulation of actin cytoskeletal reorganization. In the present study, the level of the p-LIMK1 expression was also downregulated during Trio knockdown in human cervical cancer cells.

Invasion and migration are not the only signs of tumor progression, but are also the major reasons behind failures in clinical treatment and patient deaths. Our study revealed the importance of Trio in the migration and invasion of cervical cancer. Since all active forms of proteins were reduced in Trio-deficient cells, the aberrant cell migration and invasion upon Trio knockdown may be results of lower RhoA activity, and impaired migration and invasion possibly arose from the drop in Rock and p-LIMK1 activity. The Trio/RhoA/ROCK pathway regulates the progression of cervical cancer metastasis, and blocking the Trio signaling pathway could be a feasible treatment strategy in inhibiting tumor invasion and migration. In conclusion, the present study provided evidence that Trio expression was increased in cervical cancer tissue samples, and was closely correlated with lymph node metastasis. Our findings indicate that Trio is a promising diagnostic marker for the identification of cervical cancer individuals who are at high risk of lymph node metastasis.

\section{Acknowledgements}

The present study was supported by grants from the Seed Foundation of the Second Hospital of Shandong University (grant no. 26010275618012), the Shandong Provincial Science and Technology Key Program (2016GSF201158), and the Shandong Provincial Natural Science Foundation of China (ZR2015PC020).

\section{References}

1. Schmidt S and Debant A: Function and regulation of the Rho guanine nucleotide exchange factor Trio. Small GTPases 5: e29769, 2014.

2. Bellanger JM, Lazaro JB, Diriong S, Fernandez A, Lamb N and Debant A: The two guanine nucleotide exchange factor domains of Trio link the Rac1 and the RhoA pathways in vivo. Oncogene 16: 147-152, 1998.

3. Steven R, Kubiseski TJ, Zheng H, Kulkarni S, Mancillas J, Ruiz Morales A, Hogue CW, Pawson T and Culotti J: UNC-73 activates the Rac GTPase and is required for cell and growth cone migrations in C. elegans. Cell 92: 785-795, 1998.

4. Awasaki T, Saito M, Sone M, Suzuki E, Sakai R, Ito K and Hama C: The Drosophila trio plays an essential role in patterning of axons by regulating their directional extension. Neuron 26 : 119-131, 2000.

5. Bateman J, Shu H and Van Vactor D: The guanine nucleotide exchange factor trio mediates axonal development in the Drosophila embryo. Neuron 26: 93-106, 2000.

6. Liebl EC, Forsthoefel DJ, Franco LS, Sample SH, Hess JE, Cowger JA, Chandler MP, Shupert AM and Seeger MA: Dosagesensitive, reciprocal genetic interactions between the Abl tyrosine kinase and the putative GEF trio reveal trio's role in axon pathfinding. Neuron 26: 107-118, 2000.

7. Newsome TP, Schmidt S, Dietzl G, Keleman K, Asling B, Debant A and Dickson BJ: Trio combines with dock to regulate Pak activity during photoreceptor axon pathfinding in Drosophila. Cell 101: 283-294, 2000.

8. O'Brien SP, Seipel K, Medley QG, Bronson R, Segal R and Streuli M: Skeletal muscle deformity and neuronal disorder in Trio exchange factor-deficient mouse embryos. Proc Natl Acad Sci USA 97: 12074-12078, 2000.

9. Charrasse S, Comunale F, Fortier M, Portales-Casamar E, Debant $\mathrm{A}$ and Gauthier-Rouvière C: M-cadherin activates Rac1 GTPase through the Rho-GEF trio during myoblast fusion. Mol Biol Cell 18: 1734-1743, 2007.

10. deBakker CD, Haney LB, Kinchen JM, Grimsley C, Lu M, Klingele D, Hsu PK, Chou BK, Cheng LC, Blangy A, et al: Phagocytosis of apoptotic cells is regulated by a UNC-73/ TRIO-MIG-2/RhoG signaling module and armadillo repeats of CED-12/ELMO. Curr Biol 14: 2208-2216, 2004.

11. Zheng M, Simon R, Mirlacher M, Maurer R, Gasser T, Forster T, Diener PA, Mihatsch MJ, Sauter G and Schraml P: TRIO amplification and abundant mRNA expression is associated with invasive tumor growth and rapid tumor cell proliferation in urinary bladder cancer. Am J Pathol 165: 63-69, 2004.

12. Adamowicz M, Radlwimmer B, Rieker RJ, Mertens D, Schwarzbach M, Schraml P, Benner A, Lichter P, Mechtersheimer G and Joos S: Frequent amplifications and abundant expression of Trio, $N K D 2$, and IRX2 in soft tissue sarcomas. Genes Chromosomes Cancer 45: 829-838, 2006. 
13. Lane J, Martin TA, Mansel RE and Jiang WG: The expression and prognostic value of the guanine nucleotide exchange factors (GEFs) Trio, Vav1 and TIAM-1 in human breast cancer. Int Semin Surg Oncol 5: 23, 2008.

14. Baldwin C, Garnis C, Zhang L, Rosin MP and Lam WL: Multiple microalterations detected at high frequency in oral cancer. Cancer Res 65: 7561-7567, 2005

15. Chattopadhyay I, Singh A, Phukan R, Purkayastha J, Kataki A, Mahanta J, Saxena S and Kapur S: Genome-wide analysis of chromosomal alterations in patients with esophageal squamous cell carcinoma exposed to tobacco and betel quid from high-risk area in India. Mutat Res 696: 130-138, 2010.

16. Coe BP, Henderson LJ, Garnis C, Tsao MS, Gazdar AF, Minna J, Lam S, Macaulay C and Lam WL: High-resolution chromosome arm 5p array CGH analysis of small cell lung carcinoma cell lines. Genes Chromosomes Cancer 42: 308-313, 2005.

17. Salhia B, Tran NL, Chan A, Wolf A, Nakada M, Rutka F, Ennis M, McDonough WS, Berens ME, Symons M, et al: The guanine nucleotide exchange factors trio, Ect2, and Vav3 mediate the invasive behavior of glioblastoma. Am J Pathol 173 1828-1838, 2008.

18. Wang B, Fang J, Qu L, Cao Z, Zhou J and Deng B: Upregulated TRIO expression correlates with a malignant phenotype in human hepatocellular carcinoma. Tumour Biol 36: 6901-6908, 2015.

19. Sonoshita M, Itatani Y, Kakizaki F, Sakimura K, Terashima T, Katsuyama Y, Sakai Y and Taketo MM: Promotion of colorectal cancer invasion and metastasis through activation of NOTCHDAB1-ABL-RHOGEF protein TRIO. Cancer Discov 5: 198-211, 2015.

20. Arbyn M, Castellsagué X, de Sanjosé S, Bruni L, Saraiya M, Bray F and Ferlay J: Worldwide burden of cervical cancer in 2008. Ann Oncol 22: 2675-2686, 2011.

21. Wang PP, Sun BC, Zhao JH, Chen KX, Lou YL and Hao X: Changes in incidence rates of cervical cancer in a geographically defined Chinese population and their implications in screening and education programs. Ann Epidemiol 15: 630-631, 2005.

22. Bray F, Loos AH, McCarron P, Weiderpass E, Arbyn M, Møller H, Hakama M and Parkin DM: Trends in cervical squamous cell carcinoma incidence in 13 European countries: Changing risk and the effects of screening. Cancer Epidemiol Biomarkers Prev 14: 677-686, 2005.

23. Ward KK, Shah NR, Saenz CC, McHale MT, Alvarez EA and Plaxe SC: Changing demographics of cervical cancer in the United States (1973Y2008). Gynecol Oncol 126: 330-333, 2012.

24. Qiu JT, Abdullah NA, Chou HH, Lin CT, Jung SM, Wang CC, Chen MY, Huang KG, Chang TC and Lai CH: Outcomes and prognosis of patients with recurrent cervical cancer after radical hysterectomy. Gynecol Oncol 127: 472-477, 2012.

25. Tong YQ, Liu B, Zheng HY, He YJ, Gu J, Li F and Li Y: Overexpression of BMI-1 is associated with poor prognosis in cervical cancer. Asia Pac J Clin Oncol 8: e55-e62, 2012.

26. Peng X, Wu Z, Yu L, Li J, Xu W, Chan HC, Zhang Y and Hu L: Overexpression of cystic fibrosis transmembrane conductance regulator (CFTR) is associated with human cervical cancer malignancy, progression and prognosis. Gynecol Oncol 125: $470-476,2012$
27. Cibula D, Abu-Rustum NR, Dusek L, Slama J, Zikán M, Zaal A, Sevcik L, Kenter G, Querleu D, Jach R, et al: Bilateral ultrastaging of sentinel lymph node in cervical cancer: Lowering the false-negative rate and improving the detection of micrometastasis. Gynecol Oncol 127: 462-466, 2012.

28. Choi EJ, Kim MS, Yoo NJ and Lee SH: TRIO gene encoding Trio Rho guanine nucleotide exchange factor harbors frameshift mutations of in gastric and colorectal cancers. Pathol Oncol Res: Feb 21, 2017 (Epub ahead of print). doi: 10.1007/s12253-0170211-9.

29. Pecorelli S: Revised FIGO staging for carcinoma of the vulva, cervix, and endometrium. Int J Gynaecol Obstet 105: 103-104, 2009.

30. Ma DM, Xu YP and Zhu L: Expression of vascular endothelial growth factor $\mathrm{C}$ correlates with a poor prognosis based on analysis of prognostic factors in patients with cervical carcinomas. J Obstet Gynaecol Res 37: 1519-1524, 2011.

31. Shen MX and Ding JB: Expression levels and roles of EMC-6, Beclin1, and Rab5a in the cervical cancer. Eur Rev Med Pharmacol Sci 21: 3038-3046, 2017.

32. Song Z, Zhang X, Ye X, Feng C, Yang G, Lu Y, Lin Y and Dong C: High expression of stromal cell-derived factor 1 (SDF-1) and NF- $\mathrm{KB}$ predicts poor prognosis in cervical cancer. Med Sci Monit 23: 151-157, 2017

33. Chaffer CL and Weinberg RA: A perspective on cancer cell metastasis. Science 331: 1559-1564, 2011.

34. Olson MF and Sahai E: The actin cytoskeleton in cancer cell motility. Clin Exp Metastasis 26: 273-287, 2009.

35. Ridley AJ: Rho GTPases and cell migration. J Cell Sci 114: 2713-2722, 2001.

36. Ridley AJ: Rho family proteins: Coordinating cell responses. Trends Cell Biol 11: 471-477, 2001.

37. Matsui T, Amano M, Yamamoto T, Chihara K, Nakafuku M, Ito M, Nakano T, Okawa K, Iwamatsu A and Kaibuchi K: Rho-associated kinase, a novel serine/threonine kinase, as a putative target for small GTP binding protein Rho. EMBO J 15: 2208-2216, 1996.

38. Kosako H, Yoshida T, Matsumura F, Ishizaki T, Narumiya S and Inagaki M: Rho-kinase/ROCK is involved in cytokinesis through the phosphorylation of myosin light chain and not ezrin/radixin/ moesin proteins at the cleavage furrow. Oncogene 19: 6059-6064, 2000.

39. Bourguignon LY, Zhu H, Shao L, Zhu D and Chen YW: Rho-kinase (ROK) promotes CD44v (3,8-10)-ankyrin interaction and tumor cell migration in metastatic breast cancer cells Cell Motil Cytoskeleton 43: 269-287, 1999.

40. Itoh K, Yoshioka K, Akedo H, Uehata M, Ishizaki $\mathrm{T}$ and Narumiya S: An essential part for Rho-associated kinase in the transcellular invasion of tumor cells. Nat Med 5: 221-225, 1999.

41. Li B, Zhao WD, Tan ZM, Fang WG, Zhu L and Chen YH: Involvement of Rho/ROCK signalling in small cell lung cancer migration through human brain microvascular endothelial cells. FEBS Lett 580: 4252-4260, 2006.

42. Maekawa M, Ishizaki T, Boku S, Watanabe N, Fujita A, Iwamatsu A, Obinata T, Ohashi K, Mizuno K and Narumiya S: Signaling from Rho to the actin cytoskeleton through protein kinases ROCK and LIM-kinase. Science 285: 895-898, 1999. 